\title{
Posterior foraminotomy versus anterior decompression and fusion in patients with cervical degenerative disc disease with radiculopathy: up to 5 years of outcome from the national Swedish Spine Register
}

\author{
Anna MacDowall, MD, PhD, ${ }^{1}$ Robert F. Heary, MD, ${ }^{2}$ Marek Holy, MD, ${ }^{3}$ Lars Lindhagen, $\mathrm{PhD},{ }^{4}$ and \\ Claes Olerud, MD, $\mathrm{PhD}^{1}$
}

1Department of Surgical Sciences, Uppsala University Hospital, Uppsala, Sweden; '2Department of Neurological Surgery, Rutgers New Jersey Medical School, Newark, New Jersey; ${ }^{3}$ Department of Orthopedics, Örebro University Hospital, Örebro; and ${ }^{4}$ Uppsala Clinical Research Center, Uppsala University, Uppsala, Sweden

\begin{abstract}
OBJECTIVE The long-term efficacy of posterior foraminotomy compared with anterior cervical decompression and fusion (ACDF) for the treatment of degenerative disc disease with radiculopathy has not been previously investigated in a population-based cohort.
\end{abstract}

METHODS All patients in the national Swedish Spine Register (Swespine) from January 1, 2006, until November 15, 2017, with cervical degenerative disc disease and radiculopathy were assessed. Using propensity score matching, patients treated with posterior foraminotomy were compared with those undergoing ACDF. The primary outcome measure was the Neck Disability Index (NDI), a patient-reported outcome score ranging from $0 \%$ to $100 \%$, with higher scores indicating greater disability. A minimal clinically important difference was defined as $>15 \%$. Secondary outcomes were assessed with additional patient-reported outcome measures (PROMs).

RESULTS A total of 4368 patients (2136/2232 women/men) met the inclusion criteria. Posterior foraminotomy was performed in 647 patients, and 3721 patients underwent ACDF. After meticulous propensity score matching, 570 patients with a mean age of 54 years remained in each group. Both groups had substantial decreases in their NDI scores; however, after 5 years, the difference was not significant $(2.3 \%, 95 \% \mathrm{Cl}-4.1 \%$ to $8.4 \% ; p=0.48)$ between the groups. There were no significant differences between the groups in EQ-5D or visual analog scale (VAS) for neck and arm scores. The secondary surgeries on the index level due to restenosis were more frequent in the foraminotomy group (6/100 patients vs $1 / 100)$, but on the adjacent segments there was no difference between groups (2/100).

CONCLUSIONS In patients with cervical degenerative disc disease and radiculopathy, both groups demonstrated clinical improvements at the 5 -year follow-up that were comparable and did not achieve a clinically important difference from one another, even though the reoperation rate favored the ACDF group. This study design obtains population-based results, which are generalizable.

https://thejns.org/doi/abs/10.3171/2019.9.SPINE19787

KEYWORDS posterior foraminotomy; anterior decompression and fusion; surgical outcome; Neck Disability Index; cervical radiculopathy; degenerative

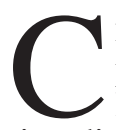

ERVICAL radiculopathy is characterized by radiating pain from the neck to the shoulder or arm. Radiculopathy is typically the consequence of degenerative disc changes such as disc herniations and/or osteophyte formations. The lower cervical segments are more frequently affected. ${ }^{8}$ When treatment with medication, therapeutic injections, and physiotherapy has failed, there are several surgical treatment options available. The most common surgery for disc-induced radiculopathy is anterior cervical decompression and fusion (ACDF). In the United States, more than 120,000 patients undergo ACDF surgery annually, with an increase of $4 \%$ per year. ${ }^{16} \mathrm{ACDF}$

ABBREVIATIONS ACDF = anterior cervical decompression and fusion; MCID = minimal clinically important difference; $\mathrm{NDI}=\mathrm{Neck}$ Disability Index; $\mathrm{PROM}=$ patientreported outcome measure; Swespine = Swedish Spine Register; VAS = visual analog scale.

SUBMITTED July 8, 2019. ACCEPTED September 10, 2019.

INCLUDE WHEN CITING Published online November 15, 2019; DOI: 10.3171/2019.9.SPINE19787. 
is believed to accelerate adjacent-segment pathology, that is, degenerative changes at the level immediately adjacent to a surgically treated level. ${ }^{8}$

Posterior cervical foraminotomy may be more costeffective, in the short term, with quicker returns to work than ACDF surgery.,26 Short-term follow-up has not demonstrated any differences in adverse events or the need for secondary surgeries. ${ }^{11}$ Higher rates of wound infections and hospital readmissions have been reported after posterior surgeries, and higher rates of postoperative dysphagia have been observed after ACDF surgery. ${ }^{30}$ Posterior foraminotomy preserves motion at the index level, but no protection against deterioration at the adjacent cervical segments has been realized in practice..$^{13,17}$ Posterior foraminotomy surgery decreased in the US from $3.4 / 100,000$ in 1992 to $1.2 / 100,000$ in $2005 .{ }^{27}$

The national Swedish Spine Register (Swespine) was founded in 1993. Cervical spine procedures have been included in Swespine since 2006. ${ }^{24}$ Using Swespine, the primary aim of this study was to compare the 5-year clinical outcome results in Neck Disability Index (NDI) in patients with cervical degenerative disc disease and radiculopathy who were treated with either posterior foraminotomy or ACDF surgery. Secondary outcomes assessed were EQ-5D scores, visual analog scale (VAS) scores for neck and arm, and secondary surgery. The hypothesis was that patients with fused levels perform equally well and do not experience more adjacent-segment pathology than do patients with preserved motion.

\section{Methods}

\section{Trial Design}

In this prospective, register-based cohort study, data were collected for all Swedish patients undergoing surgery on the cervical spine, registered in Swespine, since the registration of cervical procedures began on January 1, 2006. Final follow-up information was entered on November 15, 2017. Inclusion criteria were cervical disc herniation or foraminal stenosis with radiculopathy treated surgically with posterior foraminotomy or ACDF. ACDFs utilized plate with autograft/allograft, stand-alone cage, or cage with plate. Exclusion criteria were previous cervical surgery, presence of myelopathy, or instability.

\section{Data Collection and Outcomes}

Patients completed baseline and mailed follow-up questionnaires as well as validated patient-reported outcome measures (PROMs) without any assistance from the surgeon. ${ }^{5,24}$ Preoperative patient data included routine demographics, smoking habits, work status, sick listing, duration of neck pain, attitude toward returning to work, use of analgesics, fine motor skills, and PROMs, including NDI, EQ-5D, and VAS separately for arm and neck pain. The surgeon recorded data, including diagnosis, surgical treatment, surgical levels, neurological impairment, Ranawat grading, ${ }^{21}$ instability, type of implant, and any perioperative complications. Follow-up questionnaires and PROMs were sent to the patients after 1,2 , and 5 years postoperatively. The follow-up questionnaire included information about postoperative pain and fine motor skills, global as- sessment, sick listing, heavy work, exercise, and if the patients suffered from dysphagia or hoarseness more than 1 month postoperatively (yes/no) or had other complications (thrombosis, emboli, antibiotic treatment).

The primary outcome (NDI score) is a 10 -item, self-administered questionnaire measuring disability in patients with neck pain. The questions measure daily activities (e.g., the ability to dress, lift heavy objects, read, work, drive a car, sleep, and perform leisure activities) as well as concentration abilities and the severity of pain and headache. Each item is scored from 0 to 5 . The maximum score is 50 points, indicating severe disability, and the minimum score is 0 , indicating no disability. In order to deal with items which may have been mistakenly overlooked by the patient, the score is transformed into a percentage (range $0 \%-100 \%) .{ }^{19}$ The minimal clinically important difference (MCID) in NDI has been reported to be $15 \%-17 \% \%^{3,19,31}$ with a standard deviation of $17 \% .^{12}$

Secondary outcomes were the EQ-5D (ranging from -0.5 to 1 , with higher scores reflecting a better quality of life), EQ-5D health (ranging from 0 to 100, with higher scores indicating better health), and VAS for neck and arm pain $^{14}$ (ranging from 0 to 10 , with higher scores indicating more severe pain). The MCID is 0.24 for EQ-5D ${ }^{19}$ and 2.5 for VAS of the neck and arm. ${ }^{3}$

\section{Study Oversight}

This study was approved by the Swedish ethics review board. Since 1998, Swespine has been entirely patient based, and all participants provide oral and written informed consent. The Swespine register is owned and governed by the Swedish Society of Spinal Surgeons (www.4s.nu) with public financial support.

\section{Statistical Analysis}

Missing values were replaced with multiple imputation using chained equations as implemented in the $\mathrm{R}$ package MICE ${ }^{28}$ generating 100 imputations. These imputations were analyzed, one at a time, pooling the results using Rubin's rules. ${ }^{28}$ The following imputation models were used: predictive mean matching for numerical variables, logistic regression for dichotomous variables, and ordinal regression for ordinal variables. The proportion of missing values ranged from $0.1 \%$ for "number of degenerative levels" to $16.8 \%$ for "attitude toward returning to work after surgery."

To select confounders that might give rise to treatment selection bias, we used present knowledge and a directed acyclic graph (DAG) ${ }^{7}$ A propensity score was constructed to control for the following potential covariates: sex, age (continuous), smoking (current vs no smoking at present), BMI (continuous; $\mathrm{kg} / \mathrm{m}^{2}$ ), employed (yes vs no), sick leave (yes vs no), disability pension (yes vs no), number of degenerated levels (1-4), attitude toward returning to work after surgery (positive vs negative), and preoperative NDI (continuous).

Patients were matched 1-to-1 based on estimated propensity scores limited by the requirement that the difference between scores should be no larger than 0.005 and surgery should have taken place within 180 days. 
TABLE 1. Baseline characteristics before and after propensity score matching

\begin{tabular}{|c|c|c|c|c|c|c|}
\hline \multirow[b]{2}{*}{ Covariate } & \multicolumn{3}{|c|}{ Before Matching } & \multicolumn{3}{|c|}{ After Matching } \\
\hline & $P F(n=647)$ & $\operatorname{ACDF}(n=3721)$ & $p$ Value & $P F(n=570)$ & $\operatorname{ACDF}(n=570)$ & $\mathrm{p}$ Value \\
\hline Male, $\mathrm{n}(\%)^{*}$ & $401(62.0)$ & $1831(49.2)$ & $<0.001$ & 341 (59.8) & $329(57.7)$ & 0.47 \\
\hline Mean age, yrs (SD)* & $55.2(9.3)$ & $49.9(9.2)$ & $<0.001$ & $54.1(8.8)$ & $54.1(9.0)$ & 0.96 \\
\hline Smoking, $n(\%)^{*}$ & $112(17.3)$ & $652(17.5)$ & 0.90 & $102(17.9)$ & $102(17.9)$ & $>0.99$ \\
\hline Mean BMI (SD)* & $26.4(3.9)$ & $26.9(4.7)$ & 0.028 & $26.5(3.9)$ & $26.5(3.7)$ & 0.80 \\
\hline Unemployed, n (\%)* & $72(11.1)$ & $425(11.4)$ & 0.83 & $62(10.9)$ & $67(11.8)$ & 0.64 \\
\hline Sick leave, $\mathrm{n}(\%)^{*}$ & $223(34.5)$ & $1754(47.1)$ & $<0.001$ & $212(37.2)$ & $213(37.4)$ & 0.95 \\
\hline Disability pension, $n(\%)^{*}$ & $181(28.0)$ & $1322(35.5)$ & $<0.001$ & $170(29.8)$ & $181(31.8)$ & 0.48 \\
\hline Mean no. of levels (SD) ${ }^{*}$ & $1.65(0.8)$ & $1.35(0.5)$ & $<0.001$ & $1.52(0.7)$ & $1.55(0.6)$ & 0.53 \\
\hline Positive returning to work, $\mathrm{n}(\%)^{*}$ & $525(81.1)$ & $3084(82.9)$ & 0.28 & $469(82.3)$ & $461(80.9)$ & 0.54 \\
\hline Mean preop NDI score, \% (SD)* & $39.1(17.2)$ & $43.7(17.1)$ & $<0.001$ & $40.1(17.1)$ & $39.8(16.7)$ & 0.83 \\
\hline Pension, n (\%) & $96(14.8)$ & $279(7.5)$ & $<0.001$ & $63(11.1)$ & $71(12.5)$ & 0.46 \\
\hline Heavy work, n (\%) & $151(23.3)$ & $1000(26.9)$ & 0.06 & $145(25.4)$ & $141(24.7)$ & 0.78 \\
\hline Mean hospital time, days (SD) & $1.8(1.4)$ & $2.2(1.7)$ & $<0.001$ & $1.8(1.4)$ & $2.0(1.4)$ & $<0.001$ \\
\hline Fine motor skill, $n(\%)$ & $408(63.1)$ & $2568(69.0)$ & 0.003 & $368(64.6)$ & $376(66.0)$ & 0.62 \\
\hline Mean EQ-5D score (SD) & $0.4(0.3)$ & $0.4(0.3)$ & $<0.001$ & $0.4(0.3)$ & $0.4(0.3)$ & 0.69 \\
\hline Mean VAS-neck score (SD) & $5.7(2.6)$ & $5.9(2.5)$ & 0.06 & $5.7(2.6)$ & $5.8(2.5)$ & 0.58 \\
\hline Mean VAS-arm score (SD) & $5.4(2.7)$ & $5.7(2.6)$ & 0.007 & $5.4(2.7)$ & $5.7(2.5)$ & 0.05 \\
\hline
\end{tabular}

Matching was performed using logistic regression models with posterior foraminotomy as the outcome and the confounders as explanatory variables. The mean and SD for numerical variables and the numbers and percentages for categorical variables, before and after matching, were calculated, together with a $\mathrm{p}$ value for the null hypothesis of equal distributions. Time plots illustrate primary and secondary outcomes after 1,2 , and 5 years of follow-up. Using ANCOVA, we compared the mean 5-year outcome values between the treatment groups, adjusted for the covariates included in the propensity score and also for the baseline values for each outcome. The mean differences of the 5-year values between the groups are presented with 95\% CIs and $p$ values. A positive mean difference corresponds to higher values for posterior foraminotomy (compared with ACDF). In addition, all available cases were analyzed, including all patients who had completed each follow-up, with imputation for missing data.

Patient demographics were followed up for all available cases using linear regression for the numerical variables weight and BMI (mean differences between groups); logistic regression for the dichotomous variables pension, sick leave, disability pension, improvement of fine motor skills, working, heavy work, and dysphagia (results presented as odds ratios with fusion used as reference); and ordinal regression for postoperative sick leave and satisfaction index (odds ratios).

The mean number of complications and secondary surgeries was computed for all available cases for each group and compared using unadjusted and adjusted linear regression analyses. Reoperations on the index level and the adjacent levels were analyzed separately.
All statistical analyses were performed using R, version 3.1.0 (R Foundation for Statistical Computing).

\section{Results}

We enrolled 6052 patients, of whom 4368 met the inclusion criteria. Posterior foraminotomy had been performed in 647 patients (mean age 55 years), of whom 246 $(38 \%)$ were women and $401(62 \%)$ were men. A total of 3721 patients (mean age 50 years) had undergone ACDF, including 1890 women (51\%) and 1831 men (49\%). The percentages of smokers and the attitude toward returning to work after surgery were similar in both groups, while fine motor skills were less impaired in the foraminotomy group (408 patients [63\%]) than in the ACDF group (2568 patients [69\%]; $p=0.003)$. In the foraminotomy group, there were slightly more retired patients $(96[15 \%])$ and fewer sick-listed patients (223 [35\%]) compared with the ACDF group (279 retired patients [8\%], $\mathrm{p}<0.001$; and 1754 sick-listed patients [47\%], $\mathrm{p}<0.001)$. The mean hospital stay was $1.8 \pm 1.4$ days for the foraminotomy group and $2.2 \pm 1.7$ days for the ACDF group $(\mathrm{p}<0.001)$ (Table 1). There were 2719 of 3688 responding patients (74\%) with 1-year follow-up, 2115 of 3111 patients (68\%) with 2-year follow-up, and 1033 of 1539 patients (67\%) with 5-year follow-up (Fig. 1). After propensity score matching, 570 patients with 5-year follow-up remained in each group, and there was a good covariate balance between the groups (Table 1).

The cervical levels involved were allocated within the propensity score-matched patient groups as follows: C3-4, 48 (4.2\%); C3-5, 17 (1.5\%); C3-6, 9 (0.8\%); C3-7, 


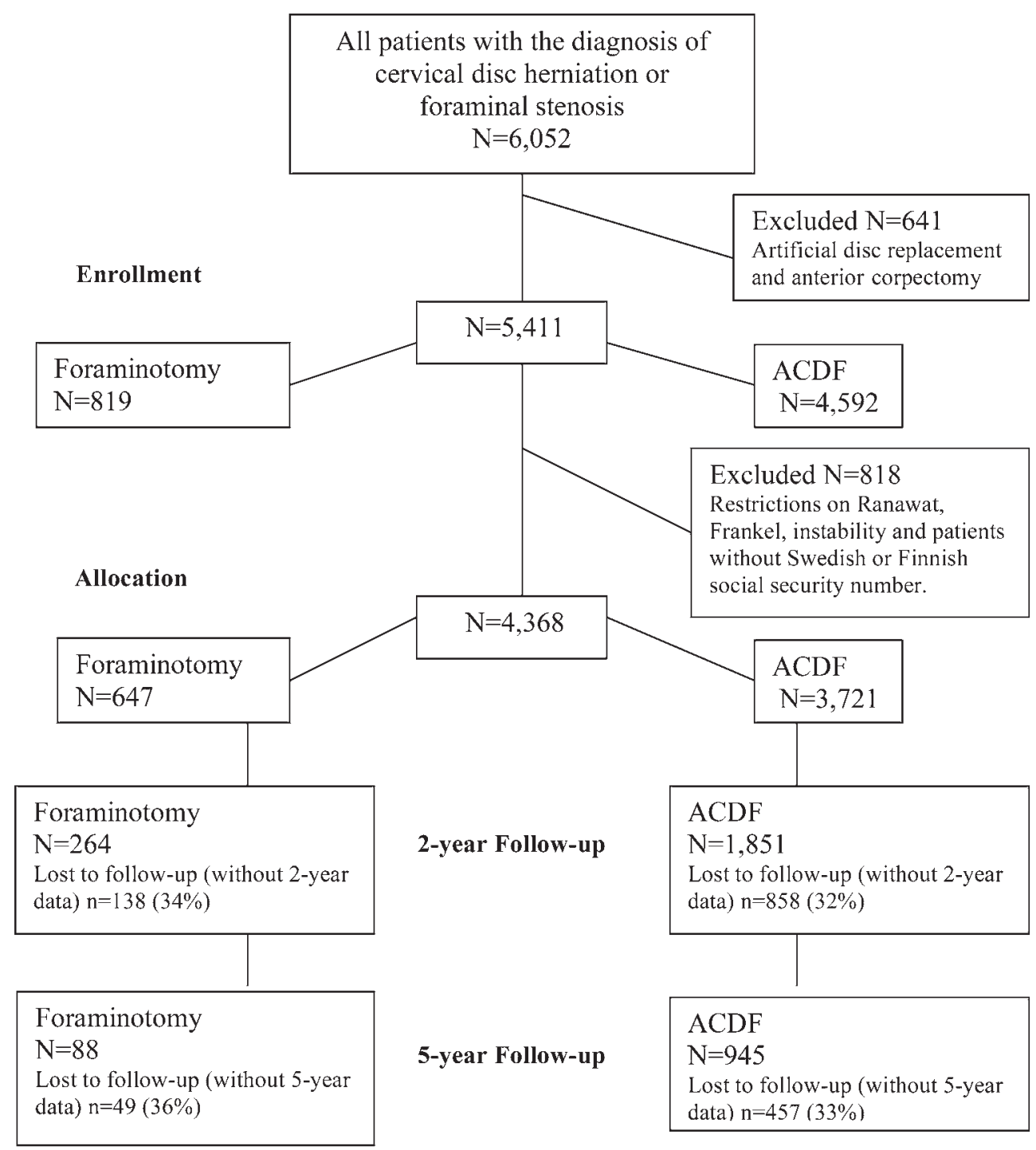

FIG. 1. CONSORT diagram. All available patients are collected at each time point; therefore, several patients in the baseline box $(n=3721)$ are not shown in the follow-up boxes because they have not yet reached 1 or 2 years of follow-up. Hence, they are not counted as lost to follow-up.

6 (0.5\%); C4-5, 51 (4.5\%); C4-6, 111 (9.7\%); C4-7, 37 (3.2\%); C5-6, $265(23.2 \%) ; \mathrm{C} 5-7,343(30.1 \%) ; \mathrm{C} 5-\mathrm{T} 1,7$ (0.6\%); C6-7, 195 (17.1\%); C6-T1, 20 (1.8\%); C7-T1, 25 (2.2\%); and missing, $6(0.5 \%)$.

\section{Outcome at 5 Years}

The foraminotomy group improved in NDI from $41.3 \%$ (95\% CI $37.6 \%-44.9 \%$ ) to $28.3 \%$ (95\% CI $23.7 \%-32.8 \%$ ), and the ACDF group improved from 40.7\% (95\% CI $36.2 \%-45.1 \%$ ) to $25.1 \%$ (95\% CI $19.8 \%-30.4 \%$ ), with a mean difference of $2.3 \%$ (95\% CI $-4.1 \%$ to $8.7 \%, \mathrm{p}=0.48)$ (Table 2 and Fig. 2).

There were no significant mean differences between groups in EQ-5D $(-0.07,95 \% \mathrm{CI}-0.18$ to $0.04 ; \mathrm{p}=0.22)$, VAS-neck $(0.69,95 \% \mathrm{CI}-0.36$ to $1.74 ; \mathrm{p}=0.20)$, or VASarm $(0.68,95 \% \mathrm{CI}-0.39$ to $1.75 ; \mathrm{p}=0.21)$ (Table 2 and Fig. 2).

\section{Follow-Up of Demographics and Secondary Surgery}

At the 1-year follow-up, more patients in the ACDF group than in the foraminotomy group reported hoarseness and dysphagia that lasted more than 1 month after surgery (OR 0.15 [95\% CI $0.08-0.29, \mathrm{p}<0.001]$ and OR 0.09 [95\% CI $0.05-0.17, \mathrm{p}<0.001]$, respectively). We observed no differences between the groups for other baseline variables (BMI, working status, sick listing, disability pension, fine motor skills, and satisfaction index).

In the posterior foraminotomy group, 38 of 358 (10.6\%) reported postoperative superficial wound healing issues compared with 80 of 2344 patients (3.4\%) treated with ACDF (raw data without imputation and before propensity score matching). After propensity score matching, the OR was 3.94 (95\% CI 1.87-8.30, p < $0.001)$. No patient in the foraminotomy group had a surgical intervention for deep infection, while 1 patient in 
the ACDF group needed revision surgery due to a deep infection.

There were no differences between groups in adverse events, 6 per 100 operations in the posterior foraminotomy group and 5 per 100 operations in the ACDF group. The most common adverse events in the posterior foraminotomy group that required intervention were postoperative hematoma ( 3 per 100 operations), dural tear ( 0.6 per 100 operations), and residual stenosis ( 0.6 per 100 operations). In the ACDF group, the most common adverse events were postoperative hematoma ( 3 per 100 operations) and dural tear ( 0.8 per 100 operations). Other complications listed were thrombosis, urinary tract infection, urinary retention, wound infection, and Horner's syndrome. There were more secondary surgeries on the index level in the foraminotomy group (6 per 100 operations) than in the fusion group ( 1 per 100 operations) $(\mathrm{p}<0.001$ for the difference between the groups in the propensity score analysis). The indication for secondary surgery on the index level in the foraminotomy group was restenosis, and the revision surgery was an ACDF. There were no differences between groups for secondary surgery on the adjacent levels, with 2 of 100 posterior foraminotomies and 2 of 100 ACDF surgeries requiring additional surgeries $(p=0.20$ in the propensity score analysis). The indication for surgery on the adjacent levels was adjacent-segment pathology, disc herniation, or foraminal stenosis in both groups. When any kind of reoperation was accounted for, at both index and adjacent levels, there were still more reoperations in the foraminotomy group, with 9 per 100 operations compared with 4 per 100 operations in the fusion group ( $<<$ 0.001 in the propensity score analysis) (Fig. 3).

\section{Sensitivity Analysis Without Propensity Score Matching}

The results of the imputation analyses of all available cases were similar to those of the propensity score matching, with no clinically significant difference between groups after 5 years of follow-up (Table 3 ).

\section{Discussion}

This is the first observational study, from a national spine registry, using PROMs that reports long-term outcomes for the treatment of cervical radiculopathy after posterior foraminotomy compared with ACDF surgery. We found no significant clinical differences in patient satisfaction or in adjacent-segment pathology, measured as secondary surgery on the adjacent levels, between the groups; however, we found a higher degree of secondary surgery due to restenosis at the index level after posterior foraminotomy.

Before propensity score matching, there were clear indications of selection differences between the patient groups: the patients receiving posterior foraminotomy were more commonly males of older age with lower baseline NDI scores and more degenerative levels, and were more often retired and less often sick listed than the patients receiving ACDF surgery. ${ }^{11}$ After propensity score matching, there were no statistically significant differences, and none of the precisions of our estimates precluded clinically important differences between the foraminoto- 

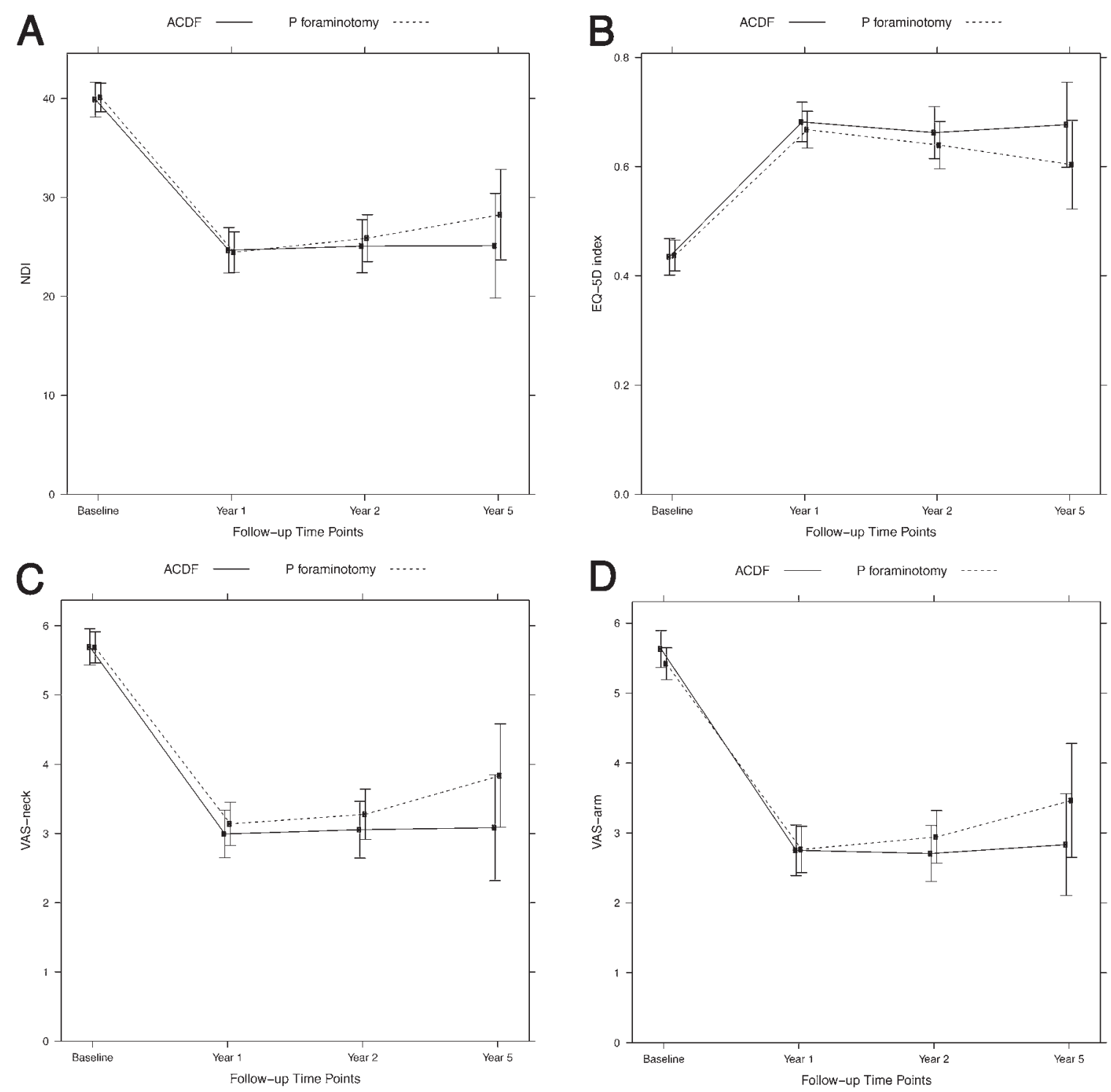

FIG. 2. Propensity score-matched data: posterior foraminotomy versus ACDF. Time plot diagrams showing the mean values of the $\mathrm{NDI}(\mathrm{A}), \mathrm{EQ}-5 \mathrm{D}(\mathrm{B})$, VAS-neck (C), and VAS-arm (D) at each time point. Error bars correspond to $95 \% \mathrm{Cls}$. $\mathrm{P}=$ posterior.

my and ACDF groups at any point. Regarding PROMs, our findings are consistent with those in other previously published randomized clinical trials. ${ }^{6,22,29}$

Secondary surgery had significantly more reoperations on the index level in the foraminotomy group due to restenosis. This differs from the literature, which reported similar numbers of secondary surgery in both posterior foraminotomies and ACDF surgeries. ${ }^{10,11}$ There seems to be some discrepancy about how much of the facet joint can or should be removed..$^{32}$ In an observational study such as this one, one would expect that the extent of facet joint resections would vary and that this factor could have influenced the stability of the posterior elements. Unfortunately, at the present time, no radiographs are accessible through Swespine. One could speculate if the secondary surgeries were, in fact, restenosis only or if some of the symptoms could have been due to instability. Other studies have suggested that up to $75 \%$ of the cervical facet joint can be removed with good clinical results, ${ }^{9}$ which presumes that preserved structures such as the disc and the longitudinal ligaments may play important roles in stabilizing the cervical spine..$^{32}$ Our study differs from others by having a larger sample size with generalizable results due to spine surgeons throughout the entire country contributing patients. After the propensity score matching was completed, there were 570 patients in each treatment arm, which makes it possible to detect even small differences between the groups. This could explain the detected differences in secondary surgeries at the index levels.

Secondary surgeries on the adjacent levels were the same in both groups. Preserved motion is believed to prevent adjacent-segment pathology; ${ }^{4}$ however, this was not 

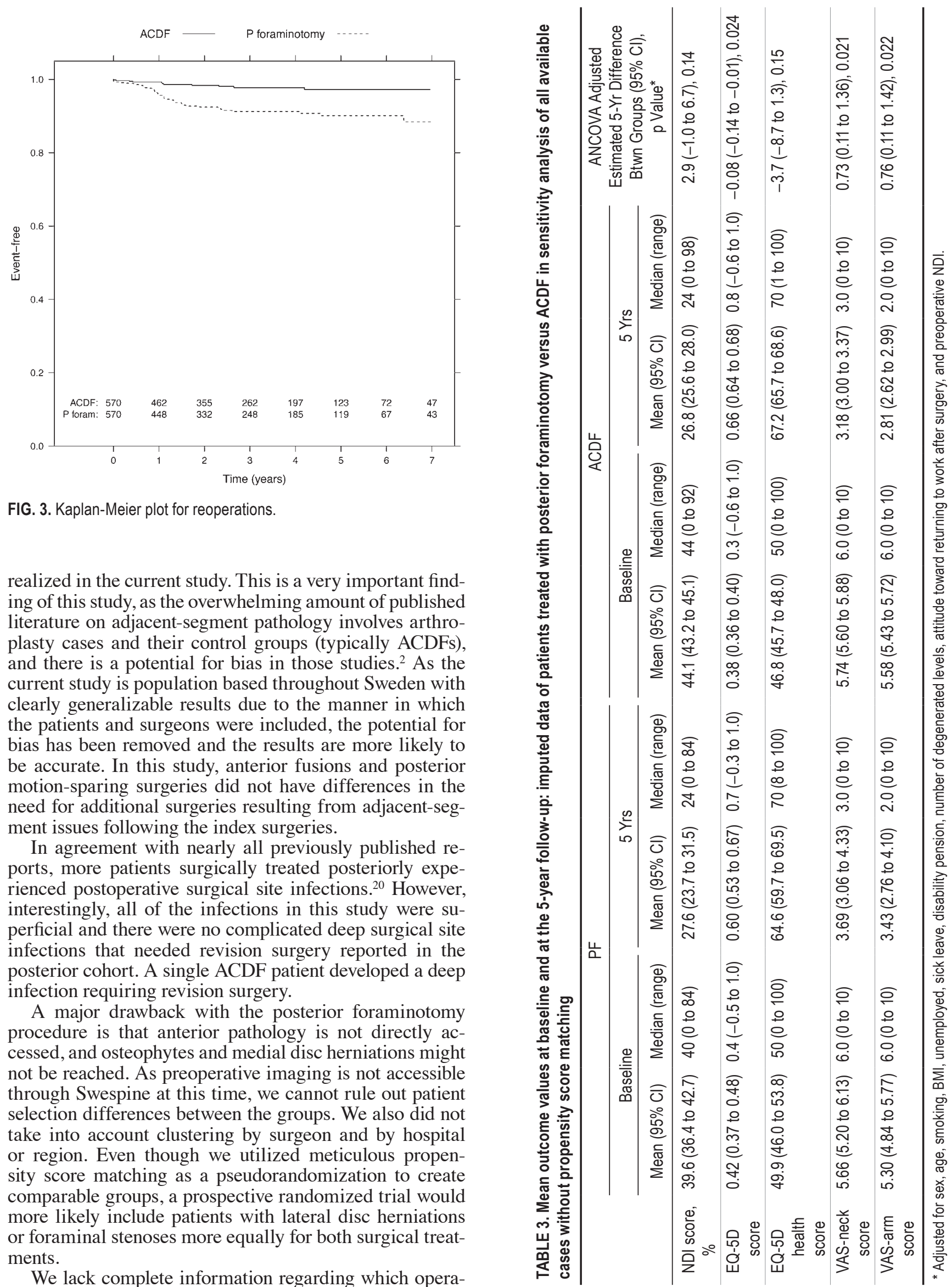

realized in the current study. This is a very important finding of this study, as the overwhelming amount of published literature on adjacent-segment pathology involves arthroplasty cases and their control groups (typically ACDFs), and there is a potential for bias in those studies. ${ }^{2}$ As the current study is population based throughout Sweden with clearly generalizable results due to the manner in which the patients and surgeons were included, the potential for bias has been removed and the results are more likely to be accurate. In this study, anterior fusions and posterior motion-sparing surgeries did not have differences in the need for additional surgeries resulting from adjacent-segment issues following the index surgeries.

In agreement with nearly all previously published reports, more patients surgically treated posteriorly experienced postoperative surgical site infections..$^{20}$ However, interestingly, all of the infections in this study were superficial and there were no complicated deep surgical site infections that needed revision surgery reported in the posterior cohort. A single ACDF patient developed a deep infection requiring revision surgery.

A major drawback with the posterior foraminotomy procedure is that anterior pathology is not directly accessed, and osteophytes and medial disc herniations might not be reached. As preoperative imaging is not accessible through Swespine at this time, we cannot rule out patient selection differences between the groups. We also did not take into account clustering by surgeon and by hospital or region. Even though we utilized meticulous propensity score matching as a pseudorandomization to create comparable groups, a prospective randomized trial would more likely include patients with lateral disc herniations or foraminal stenoses more equally for both surgical treatments.

We lack complete information regarding which opera- 
tive technique for posterior foraminotomy was performed (minimally invasive, endoscopic, or traditional open techniques), ${ }^{29}$ or if the disc herniation was removed during posterior nerve root decompression. As no differences in outcomes between the various techniques for posterior foraminotomy have been established,,$^{15,23}$ we do not believe that these surgical technique differences would affect the results of the current study.

Other limitations of this study include the patients lost to follow-up: $26 \%$ in year $1,32 \%$ in year 2, and $33 \%$ in year 5 . While the specific data regarding the index surgeries are all included in Swespine, the accuracy of information on delayed complications or reoperations is likely less stringently reported..$^{18}$ Nonetheless, we find it unlikely that this is method related, and as such, it should affect both treatment groups equally. We made an intention-to-treat analysis and no per-protocol analysis. As this is an observational large cohort and not a randomized controlled trial, we have less control over the actual reoperation rates and are dependent on the numbers that are reported by others in the register. Therefore, a per-protocol analysis would be unreliable. Nonetheless, the backside of an intention-totreat analysis is that in this case, failed foraminotomies reoperated as ACDFs are still analyzed as foraminotomies and may skew the data in favor of foraminotomy outcome. The 5-year results should be interpreted with the knowledge of this statistical weakness.

Our study has several strengths. First, Swespine is a nationwide register using validated instruments with prospectively collected data. Second, in 2016, $90 \%$ of the spine clinics in Sweden were affiliated, and the register completeness was 75\% (www.swespine.se). ${ }^{5,25}$ Therefore, these results reflect a national setting with widely generalizable results. At the present time, data continue to be collected in Swespine, and 10-year outcomes are planned for future evaluation when these data become fully available.

\section{Conclusions}

We found no clinically significant differences in primary or secondary outcomes between the posterior foraminotomy and ACDF groups in the short term or during long-term follow-up. There were more revisions at the index levels in the foraminotomy group, and the adjacent segments had no differences between the motion-sparing foraminotomy group and the ACDF group.

\section{Acknowledgments}

We thank Carina Blom at the Swedish Society of Spinal Surgeons and the Swedish Spine Study Group for handling the Swedish Spine Registry.

\section{References}

1. Alvin MD, Lubelski D, Abdullah KG, Whitmore RG, Benzel EC, Mroz TE: Cost-utility analysis of anterior cervical discectomy and fusion with plating (ACDFP) versus posterior cervical foraminotomy (PCF) for patients with single-level cervical radiculopathy at 1-year follow-up. Clin Spine Surg 29:E67-E72, 2016

2. Bartels RH: Influence of industry on scientific reports. Eur Spine J 22:1690-1691, 2013

3. Carreon LY, Glassman SD, Campbell MJ, Anderson PA:
Neck Disability Index, short form-36 physical component summary, and pain scales for neck and arm pain: the minimum clinically important difference and substantial clinical benefit after cervical spine fusion. Spine J 10:469-474, 2010

4. Chin-See-Chong TC, Gadjradj PS, Boelen RJ, Harhangi BS: Current practice of cervical disc arthroplasty: a survey among 383 AOSpine International members. Neurosurg Focus 42(2):E8, 2017

5. Fritzell P, Hägg O, Gerdhem P, Abbott A, Songsong A, Parai C, et al: Swespine Årsrapport 2017. Swedish Society of Spinal Surgeons (4s.nu/pdf/170925_Svenska_ryggregistret_arsrapport\%202017_SENT.pdf) [Āccessed September 18, 2019]

6. Herkowitz HN, Kurz LT, Overholt DP: Surgical management of cervical soft disc herniation. A comparison between the anterior and posterior approach. Spine (Phila Pa 1976) 15:1026-1030, 1990

7. Hernán MA, Hernández-Díaz S, Werler MM, Mitchell AA: Causal knowledge as a prerequisite for confounding evaluation: an application to birth defects epidemiology. Am J Epidemiol 155:176-184, 2002

8. Hilibrand AS, Carlson GD, Palumbo MA, Jones PK, Bohlman HH: Radiculopathy and myelopathy at segments adjacent to the site of a previous anterior cervical arthrodesis. J Bone Joint Surg Am 81:519-528, 1999

9. Jagannathan J, Sherman JH, Szabo T, Shaffrey CI, Jane JA: The posterior cervical foraminotomy in the treatment of cervical disc/osteophyte disease: a single-surgeon experience with a minimum of 5 years' clinical and radiographic followup. J Neurosurg Spine 10:347-356, 2009

10. Liu WJ, Hu L, Chou PH, Wang JW, Kan WS: Comparison of anterior cervical discectomy and fusion versus posterior cervical foraminotomy in the treatment of cervical radiculopathy: a systematic review. Orthop Surg 8:425-431, 2016

11. Lubelski D, Healy AT, Silverstein MP, Abdullah KG, Thompson NR, Riew KD, et al: Reoperation rates after anterior cervical discectomy and fusion versus posterior cervical foraminotomy: a propensity-matched analysis. Spine J 15:1277-1283, 2015

12. MacDowall A, Canto Moreira N, Marques C, Skeppholm M, Lindhagen L, Robinson Y, et al: Artificial disc replacement versus fusion in patients with cervical degenerative disc disease and radiculopathy: a randomized controlled trial with 5-year outcomes. J Neurosurg Spine 30:323-331, 2019

13. MacDowall A, Skeppholm M, Lindhagen L, Robinson Y, Löfgren H, Michaëlsson K, et al: Artificial disc replacement versus fusion in patients with cervical degenerative disc disease with radiculopathy: 5-year outcomes from the National Swedish Spine Register. J Neurosurg Spine 30:159-167, 2018

14. MacDowall A, Skeppholm M, Robinson Y, Olerud C: Validation of the visual analog scale in the cervical spine. J Neurosurg Spine 28:227-235, 2018

15. McAnany SJ, Kim JS, Overley SC, Baird EO, Anderson PA, Qureshi SA: A meta-analysis of cervical foraminotomy: open versus minimally-invasive techniques. Spine J 15:849-856, 2015

16. Nesterenko SO, Riley LH III, Skolasky RL: Anterior cervical discectomy and fusion versus cervical disc arthroplasty: current state and trends in treatment for cervical disc pathology. Spine (Phila Pa 1976) 37:1470-1474, 2012

17. Nunley PD, Jawahar A, Cavanaugh DA, Gordon CR, Kerr EJ III, Utter PA: Symptomatic adjacent segment disease after cervical total disc replacement: re-examining the clinical and radiological evidence with established criteria. Spine J 13:5-12, 2013

18. Öhrn A, Olai A, Rutberg H, Nilsen P, Tropp H: Adverse events in spine surgery in Sweden: a comparison of patient claims data and national quality register (Swespine) data. Acta Orthop 82:727-731, 2011 
19. Parker SL, Godil SS, Shau DN, Mendenhall SK, McGirt MJ: Assessment of the minimum clinically important difference in pain, disability, and quality of life after anterior cervical discectomy and fusion: clinical article. J Neurosurg Spine 18:154-160, 2013

20. Pull ter Gunne AF, Cohen DB: Incidence, prevalence, and analysis of risk factors for surgical site infection following adult spinal surgery. Spine (Phila Pa 1976) 34:1422-1428, 2009

21. Ranawat CS, O'Leary P, Pellicci P, Tsairis P, Marchisello P, Dorr L: Cervical spine fusion in rheumatoid arthritis. J Bone Joint Surg Am 61:1003-1010, 1979

22. Ruetten S, Komp M, Merk H, Godolias G: Full-endoscopic cervical posterior foraminotomy for the operation of lateral disc herniations using 5.9-mm endoscopes: a prospective, randomized, controlled study. Spine (Phila Pa 1976) 33:940-948, 2008

23. Skovrlj B, Gologorsky Y, Haque R, Fessler RG, Qureshi SA: Complications, outcomes, and need for fusion after minimally invasive posterior cervical foraminotomy and microdiscectomy. Spine J 14:2405-2411, 2014

24. Strömqvist B, Fritzell P, Hägg O, Jönsson B: The Swedish Spine Register: development, design and utility. Eur Spine J 18 (Suppl 3):294-304, 2009

25. Strömqvist B, Jönsson B, Fritzell P, Hägg O, Larsson BE, Lind B: The Swedish national register for lumbar spine surgery: Swedish Society for Spinal Surgery. Acta Orthop Scand 72:99-106, 2001

26. Tumialán LM, Ponton RP, Gluf WM: Management of unilateral cervical radiculopathy in the military: the cost effectiveness of posterior cervical foraminotomy compared with anterior cervical discectomy and fusion. Neurosurg Focus 28(5):E17, 2010

27. Wang MC, Kreuter W, Wolfla CE, Maiman DJ, Deyo RA: Trends and variations in cervical spine surgery in the United States: Medicare beneficiaries, 1992 to 2005. Spine (Phila Pa 1976) 34:955-963, 2009

28. White IR, Royston P, Wood AM: Multiple imputation using chained equations: issues and guidance for practice. Stat Med 30:377-399, 2011
29. Wirth FP, Dowd GC, Sanders HF, Wirth C: Cervical discectomy. A prospective analysis of three operative techniques. Surg Neurol 53:340-348, 2000

30. Witiw C, Smieliauskas F, O'Toole JE, Fehlings MG, Fessler RG: Comparison of anterior cervical discectomy and fusion to posterior cervical foraminotomy for cervical radiculopathy: utilization, costs, and adverse events 2003 to 2014. Neurosurgery 84:413-420, 2019

31. Young IA, Cleland JA, Michener LA, Brown C: Reliability, construct validity, and responsiveness of the neck disability index, patient-specific functional scale, and numeric pain rating scale in patients with cervical radiculopathy. Am J Phys Med Rehabil 89:831-839, 2010

32. Zdeblick TA, Zou D, Warden KE, McCabe R, Kunz D, Vanderby R: Cervical stability after foraminotomy. A biomechanical in vitro analysis. J Bone Joint Surg Am 74:22-27, 1992

\section{Disclosures}

Dr. Heary: royalties from Zimmer Spine and Thieme Medical Publishers, president of the Lumbar Spine Research Society, and vice president of the American Association of Neurological Surgeons. Dr. Olerud: paid speaker for Johnson \& Johnson; speakers bureau of Anatomica, AOSpine, DePuy Synthes, and Medtronic; and board member of Cervical Spine Research Society Europe.

\section{Author Contributions}

Conception and design: MacDowall, Holy, Olerud. Acquisition of data: MacDowall. Analysis and interpretation of data: MacDowall. Drafting the article: MacDowall. Critically revising the article: Heary, Olerud. Reviewed submitted version of manuscript: Heary, Olerud. Statistical analysis: Lindhagen. Administrative/ technical/material support: Holy. Study supervision: Olerud.

\section{Correspondence}

Anna MacDowall: Uppsala University Hospital, Uppsala, Sweden. anna.mac.dowall@akademiska.se. 